\title{
Multiple effects of trace elements on methanogenesis in a two-phase anaerobic membrane bioreactor treating starch wastewater
}

\author{
Dawei Yu ${ }^{1}$ (D) $\cdot$ Chao $\mathrm{Li}^{2} \cdot$ Lina Wang ${ }^{3} \cdot$ Junya Zhang $^{1} \cdot$ Jing Liu $^{2} \cdot$ Yuansong Wei ${ }^{1,4}$
}

Received: 15 October 2015 /Revised: 29 December 2015 / Accepted: 30 December 2015 /Published online: 15 February 2016

(C) Springer-Verlag Berlin Heidelberg 2016

\begin{abstract}
For enhancing anaerobic membrane bioreactor (AnMBR) treating food processing wastewater due to speedlimited methanogenesis step, multiple effects of trace element (TE) supplementation on methanogenesis of a two-phase AnMBR were firstly investigated in batch tests. TE supplementation included individual element, combination and recovery of $\mathrm{Fe}, \mathrm{Ni}, \mathrm{Co}, \mathrm{Cu}$ and $\mathrm{Zn}$ supplementation. Multiple effects of TE supplementation were highest stimulated by $22.4 \pm 5.6 \%$ (TE313) for chemical oxygen demand (COD) removal, $43.1 \pm 12.5 \%$ (TE303) for specific methanogenic activity (SMA) and $13.9 \pm 3.7 \%$ (TE405) for biomass growth, respectively, although only $7.5 \pm 0.6 \%$ (TE106) for methane production. Dosage of TEs played a critical role in methane production, COD removal and biomass growth of the AnMBR's methanogenesis. Low dosages of TE supplementation improved the COD removal and slightly stimulated the
\end{abstract}

Dawei $\mathrm{Yu}$ and Chao Li contributed equally to this work.

Electronic supplementary material The online version of this article (doi:10.1007/s00253-016-7289-y) contains supplementary material, which is available to authorized users.

Jing Liu

jing.liu@biotek.lu.se

Yuansong Wei

yswei@rcees.ac.cn

1 State Key Joint Laboratory of Environmental Simulation and Pollution Control, Research Center for Eco-Environmental Sciences, Chinese Academy of Sciences, Beijing, China

2 Department of Biotechnology, Lund University, Naturvetarvägen 14, SE-221 00 Lund, Sweden

3 School of Environment, Beijing Normal University, Beijing, China

4 Research Center for Eco-Environmental Sciences, Chinese Academy of Sciences, Beijing 100085, China
COD bioconverting to methane and biomass, but their specific methanation activities were inhibited in the initial rapid methanogenesis stage. Several methanation functional species were increased in abundance like Methanosarcina and Methanoculleus.

Keywords Methanogenesis $\cdot$ Trace element $\cdot$ Biochemical methanation potential $\cdot$ High-throughput sequencing

\section{Introduction}

Food processing wastewater treatment in China meets a rising challenge and has been paid intense attention with stringent discharging standard and environmental pressure. Due to a high chemical oxygen demand (COD) strength and large COD discharging quantity of $4.71 \times 10^{6} \mathrm{t}$ in 2013 , the food processing wastewater has been listed in the top 3 among 41 key industrial wastewaters in China. As typical food processing wastewater, starch wastewater and sugar wastewater are well known as high COD strength in a range of $10-30 \mathrm{~g} \mathrm{~L}^{-1}$ (Fang et al. 2011; Ministry of Environmental Protection. 2015; Wei et al. 2014b). Therefore, COD removal and methane recovery are highly emphasized on food processing wastewater, which has been listed on the top $10 \mathrm{key}$ industrial wastewaters in the Action Plan for Water Pollution Prevention and Control issued (State Council of China. 2015). Therefore, advanced technologies for COD removal of food processing wastewater are urgently needed in China.

Anaerobic membrane bioreactor (AnMBR) is a promising anaerobic digestion (AD) technology for high-COD food processing wastewater treatment, by which both energy recovery and COD removal can be achieved simultaneously (Smith et al. 2014). Conventionally, food processing wastewater in China is treated by combined processes of sedimentation, $\mathrm{AD}$ 
and activated sludge processes, but it needs very high investment and operational cost for such multiple treatment steps to meet requirements of COD removal from $10 \sim 30 \mathrm{~g} \mathrm{~L}^{-1}$ to $500 \mathrm{mg} \mathrm{L}^{-1}$ according to the integrated wastewater discharge standard of China (GB 8978-1996). Comparing with the conventional combined process of $\mathrm{AD}$ and activated sludge process, high-strength wastewater treatment by AnMBR can benefit in lower energy recovery cost and cleaner effluent based on life cycle assessment (Smith et al. 2014). Comparing with conventional AD, AnMBR not only recovered $15 \%$ more net energy for high-strength wastewater (Smith et al. 2014), but also had higher COD removal rate and low effluent COD, e.g. $98 \%$ and $300 \mathrm{mg} \mathrm{L}^{-1}$, respectively (Yanagi et al. 1994). Such advantages make AnMBR an attractive new cost-efficient and shot-cut technology for food processing wastewater treatment that can meet the stringent discharging standard of COD in food processing wastewater.

One of current obstacles to intensify AnMBR in practice was speed limited by methanogenesis in food processing wastewater treatment. According to fermentation time, anaerobic digestion (AD) can be classified as two typical speedlimited classes: (a) hydrolysis limited and (b) methanogenesis limited (Wei et al. 2014b). Due to high biodegradability of food processing wastewater, the speed limit step for $\mathrm{AD}$ treating food processing wastewater is the methanogenesis step. One of its counter measures is to provide sufficient time for methanogenesis step by prolonged sludge retention times (SRTs). But, prolonged SRT of AnMBR results in a decrease of methanogenesis activity due to sludge aging (Han et al. 2005; Ho and Sung 2010). Methanogenesis activity of AnMBR was also inhibited by high shear condition in tubular membrane modules (Padmasiri et al. 2007). AD limited by methanogenesis is thus much more serious and challenging in the AnMBR than the conventional AD. Therefore, there are urgent demands in overcoming this technical challenge of methanogenesis-limited AD especially for the AnMBR treating food processing wastewater.

Preciously suggested approach to stimulate methanogenesis was addition of trace elements (TEs) based on mechanisms of micronutrition and relief inhibition by metal sulphur (Ahring 2003; Mao et al. 2015). For example, TEs were supplied in 60 $\mathrm{AD}$ plants with low micronutrient levels, and digester performance was improved after supplementation (Lindorfer et al. 2012). Although consensus has been made that TE supplementation can stabilize $\mathrm{AD}$ operation, different species and dosages of TEs were reported with large variations (Osuna et al. 2003; Wall et al. 2014). For instance, TE supplementation (500 mg $\mathrm{Fe} \mathrm{L}^{-1}, 0.5 \mathrm{mg} \mathrm{Co} \mathrm{L}^{-1}$ and $0.25 \mathrm{mg} \mathrm{Ni} \mathrm{L}^{-1}$ ) has been reported to improve the performance of biogas process operating with syntrophic acetate oxidation as the dominating mechanism for methane formation (Karlsson et al. 2012). It was found that TE mixture (2.0 mg Co L ${ }^{-1}, 5.0 \mathrm{mg} \mathrm{Mo} \mathrm{L}^{-1}, 10.0 \mathrm{mg} \mathrm{Ni} \mathrm{L}^{-1}$ and $100 \mathrm{mg} \mathrm{Fe} \mathrm{L}^{-1}$ ) can contribute to long-term stability of single- stage $\mathrm{AD}$, and $\mathrm{Fe}$ was identified as the most effective species (Zhang and Jahng 2012). Nickel is essential for the activity of many hydrogenases and component of F430 coenzyme, which is important for both fermentative and methanogenic microorganisms (Scheller et al. 2010). What is more, metal-enzyme's role in metabolic pathway indicated that TEs played a critical role in methanogenesis rather than acidogenesis. However, overdosing of TEs can also have a negative impact; i.e. higher dosages of TEs are reviewed as inhibitors of AD (Chen et al. 2008). The reported inhibition concentration of TEs that caused $50 \%$ reduction in accumulated methane production was different, such as $20 \mathrm{mg} \mathrm{Cu} \mathrm{L}^{-1}$ or $14 \mathrm{mg} \mathrm{K} \mathrm{L}^{-1}$. Therefore, TE supplementation strategies including species and dosage are critical for stimulation of AD limited by methanogenesis and should be optimized for high-COD wastewater treatment by AnMBR.

According to the mechanisms of TEs stimulating AD, TEs should bring more multiple effects on methanogenesis than stimulation and stabilization of methane production which was widely reported in conventional AD. In general, TEs stimulate $\mathrm{AD}$ as critical micronutrition through (1) composing metal enzyme and metal coenzyme, (2) activating enzyme and coenzyme and (3) relieving sulphur or ammonia inhibition (Ahring 2003; Mao et al. 2015). According to these mechanisms, many related effects should be observed in TE addition, such as more methane production due to inhibition relieved, higher activity of methanogenic microorganisms due to enzyme catalyse, more biomass growth due to sufficient micronutrition and, thus, higher COD removal (Sambusiti et al. 2014). Then, downstream treatment could be benefited from lower effluent COD, which could be accomplished by enhancing COD removal of AnMBR with extra TEs (Smith et al. 2014). Lindorfer reported that enhanced digester performance was accompanied by increased bacterial biomass (Lindorfer et al. 2012). Osuna mentioned that degradation rates of specific substrate were not affected while the maximum specific activity of methanogens was stimulated (Florencio et al. 1993; Osuna et al. 2003). To sum up, there are four critical effects of methanogenesis induced by TE supplementation including more methane production, higher activity of methanogenic microorganisms, more biomass growth and higher COD removal, which are vital to AnMBR, but their combined or synergistic interactions were remaining ambiguous.

Therefore, a two-phase AnMBR treating starch wastewater and five TEs ( $\mathrm{Fe}, \mathrm{Ni}, \mathrm{Co}, \mathrm{Cu}$ and $\mathrm{Zn}$ ) were selected in this study, and the objective of this paper was to simultaneously investigate the multiple effects of TE supplementation on methanogenesis, including COD removal, methane production, methanogen activity $\mathrm{n}$ and biomass growth. Meanwhile, microbial community structure succession and methanation functional species shifts were analysed, and TE supplementation strategies for the two-phase AnMBR treating starch wastewater were discussed. 


\section{Material and methods}

\section{Configuration of the two-phase AnMBR}

A lab scale of the two-phase AnMBR was set up for treating starch wastewater (Fig. 1), and the anaerobic digester was separated as acidogenesis and methanogenesis phases. The acidogenesis phase is set as an anaerobic baffle reactor (ABR), which is a cylinder divided into four upflow zones by two baffles aiming to improve acidogen retention. The methanogenesis phase is set as a continuous stirred tank reactor (CSTR), using a modified control system and a BLBIO-5GCA lab fermenter (Shanghai Bailun Bio-Technology Co., Ltd., China). The working volumes of these two reactors are 2 and $4 \mathrm{~L}$, respectively. Both reactors were equipped with an online $\mathrm{pH}$ and an ORP sensor (Hach Co., USA) for process monitoring. The $\mathrm{pH}$ in the methanogenesis phase was controlled no less than 7.0 with automatic dosing of $\mathrm{NaOH}$ solution $(1 \mathrm{M})$. A high-precision gas meter ( $\mu$-Flow, $10-4000 \mathrm{~mL} \mathrm{~h}^{-1}$ Bioprocess Control AB., Sweden) was installed for online monitoring biogas production in the methanogenesis phase. Temperatures for both phases were maintained at $37 \pm 2$ and $37 \pm 0.3{ }^{\circ} \mathrm{C}$ by electrical heating and water bath, respectively.

A tubular membrane (PVDF, $0.01 \mathrm{~m}^{2}, 200,000 \mathrm{Da}$ of molecular weight cut-off (MWCO), Berghof Membrane Technology GmbH, Germany) was externally coupled with the methanogenesis phase by a centrifugal pump (OW370A, Taizhou Qibo Tools Co., Ltd., China) to create cross flow. The cross flow was continually operated at rate of $3 \mathrm{~m} \mathrm{~s}^{-1}$ in order to make the tubular membrane endure higher solid concentration.

\section{Operation of the two-phase AnMBR}

The two-phase reactors were started with anaerobic sludge from a municipal sewage treatment plant of Xiaohongmen Wastewater Treatment Plant, Beijing, China. The reactor was fed with starch wastewater obtained from Chengde Honhuishuanghe Starch Co., Ltd, Hebei province, China. The AnMBR was started at organic loading rate (OLR) of $5.88 \pm 0.63 \mathrm{~kg} \mathrm{COD} \mathrm{m}^{-3}$ day $^{-1}$ in the methanogenesis phase (Fang et al. 2011). The OLR was controlled according to influent weight by electronic balance (TD10000, 0 10,000 $\pm 0.1 \mathrm{~g}$, Tianjin Tianma Ltd., China). The fed wastewater was characterized as Table 1 including COD $(27,610$ $\pm 3490 \mathrm{mg} \mathrm{L}^{-1}$ ) and TEs. The $\mathrm{Fe} / \mathrm{COD}, \mathrm{Co} / \mathrm{COD}$ and $\mathrm{Ni} /$ COD of fed wastewater indicate lack of TE, which is 224, 0.94 and $1.42 \mathrm{mg} \mathrm{kg}^{-1}$, respectively (Qiang et al. 2012).

The operation performance of the AnMBR was stable, which was judged according to the successful of two-phase separation and effluent COD met with the GB8978-1996 discharging standard of $500 \mathrm{mg} \mathrm{L}^{-1}$. The $\mathrm{pH}$ of acidogenesis phase gradually decreased from $7.31 \pm 0.03$ to $4.65 \pm 0.09$ in 20 days. The MLSS and MLVSS concentrations were stabilized at $11,930 \pm 3714$ and $7759 \pm 1026 \mathrm{mg} \mathrm{L}^{-1}$ during 51th to 75 th day, respectively. And, biogas production rate and biogas yield of methanogenesis phase stabilized at 291 $\pm 106 \mathrm{NmL} \mathrm{h}^{-1}$ and $275 \pm 61 \mathrm{NmL} \mathrm{g} \mathrm{COD}_{\text {in }}{ }^{-1}$ (Qiang et al. 2012), respectively. Meanwhile, the related HRT and SRT were $60 \mathrm{~h}$ and 200 days, respectively. The effluent COD of AnMBR was $356.22 \pm 66.75 \mathrm{mg} \mathrm{L}^{-1}$ from the 51th to 75 th day, which stably met with the discharging standard. More details of the AnMBR were also reported (Yu et al. 2016).
Fig. 1 Schematic diagram of a two-phase anaerobic tubular membrane bioreactor

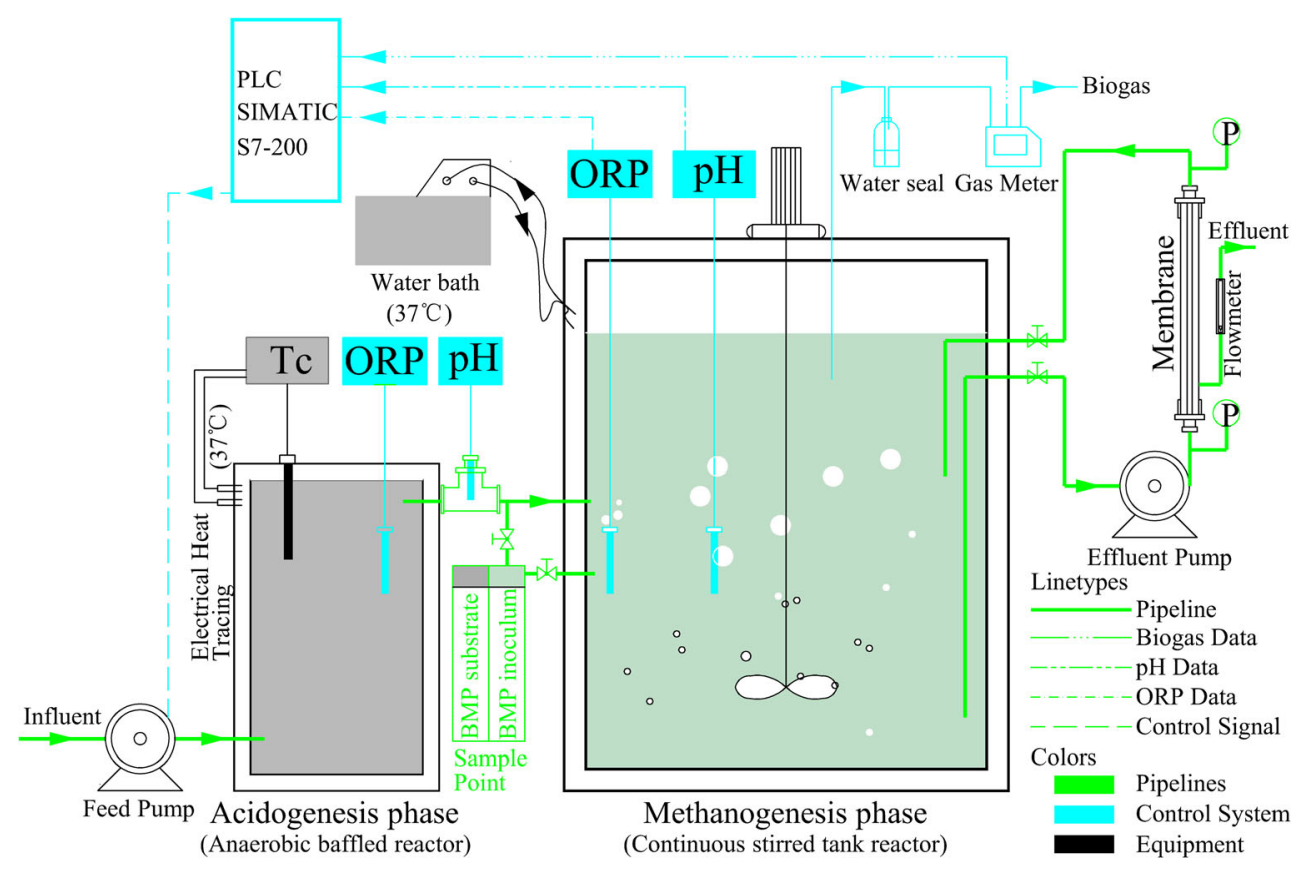


Table 1 Characteristics of feed starch wastewater

\begin{tabular}{rrrl}
\hline Feed starch wastewater (average $\pm \mathrm{SD})$ & & \\
$\mathrm{COD}\left(\mathrm{g} \mathrm{L}^{-1}\right)$ & $27.61 \pm 3.49$ & Total solid $\left(\mathrm{g} \mathrm{L}^{-1}\right)$ & $9.21 \pm 1.06$ \\
$\mathrm{NH}_{4}{ }^{+}-\mathrm{N}\left(\mathrm{mg} \mathrm{L}^{-1}\right)$ & $518.57 \pm 232.96$ & Volatile solids $\left(\mathrm{g} \mathrm{L}^{-1}\right)$ & $6.21 \pm 0.84$ \\
$\mathrm{NO}_{3}{ }^{+}-\mathrm{N}\left(\mathrm{mg} \mathrm{L}^{-1}\right)$ & $12.81 \pm 6.83$ & $\mathrm{pH}$ & $4.86 \pm 0.85$ \\
$\mathrm{TN}\left(\mathrm{mg} \mathrm{L}^{-1}\right)$ & $559.77 \pm 23.7$ & $\mathrm{ORP}(\mathrm{mV})$ & $27.06 \pm 113.66$ \\
$\mathrm{PO}_{4}{ }^{3-}-\mathrm{P}\left(\mathrm{mg} \mathrm{L}^{-1}\right)$ & $281.37 \pm 20.41$ & Electrical conductivity $\left(\mathrm{mS} \mathrm{cm}^{-1}\right)$ & $7.10 \pm 0.71$ \\
$\mathrm{TOC}\left(\mathrm{mg} \mathrm{L}^{-1}\right)$ & $7531.00 \pm 1678.2$ & $\mathrm{TIC}\left(\mathrm{mg} \mathrm{L}^{-1}\right)$ & $389.05 \pm 313.78$ \\
Trace metals (average $\pm \mathrm{SD}, \mathrm{mg} \mathrm{L})^{-1}$ & & \\
$\mathrm{Fe}$ & $13.48+6.69$ & $\mathrm{Zn}$ & $0.94+0.2$ \\
$\mathrm{Ni}$ & $0.04+0.05$ & $\mathrm{Al}$ & $0.5+1.43$ \\
$\mathrm{Co}$ & $0.03+0.04$ & $\mathrm{Mg}$ & $88.06+6.98$ \\
$\mathrm{Cu}$ & $0.34+0.14$ & $\mathrm{Mn}$ & $0.42+0.11$ \\
\hline
\end{tabular}

${ }^{\mathrm{a}}$ Trace metals Mn, As, $\mathrm{Cd}$ and $\mathrm{Cr}$ were under detection limit of ICP-OES
The TE composition of the wastewater was analysed with an ICP-OES monthly (Table 1 and Fig. S1).

As mechanisms of TEs reveal that TEs played more critical roles in methanogenesis rather than acidogenesis, effluents from the acidogenesis phase and the methanogenesis phase were sampled as substrate and inoculum for biochemical methane potential (BMP) tests of TE supplementation, respectively. Both the substrate and inoculum were analysed before BMP tests. Total solid (TS) and volatile solid (VS) were determined using APHA methods. COD was measured using DR2500 (HACH Inc., USA) according to Chinese standard methods (GB11914-1989). Total carbon (TC), total organic carbon (TOC) and total inorganic carbon (TIC) were determined with a liquiTOC II (Elementar Analysensysteme $\mathrm{GmbH}$, Germany). Before BMP tests, each inoculum was pre-cultured for $12 \mathrm{~h}$ to reduce background biogas generation (Sambusiti et al. 2014). After pre-culture, the inoculum and substrate were mixed in the BMP reactor according to the same OLR as that in the operating methanogenesis phase of the two-phase AnMBR at $5.88 \pm 0.63 \mathrm{~kg} \mathrm{COD} \mathrm{m}^{-3}$ day $^{-1}$.

\section{Methanogenesis performance tests}

Methanogenesis performance was determined and evaluated by COD removal, methane production by biochemical methane potential (BMP) test, specific methanogenic activity (SMA) test and VS changes for biomass growth. Tests of BMP and SMA were carried out in duplicate using a commercial laboratory instrument (AMPTS II, Bioprocess Control, Sweden) which contains 15 parallel cells. Each cell consists of three parts including reactor, $\mathrm{CO}_{2}$ absorption and gas meter. The reactor is an interval stir glass bottle $(500 \mathrm{~mL}$ of working volume) placed in a water bath at $37 \pm 0.5^{\circ} \mathrm{C}$. The $\mathrm{CO}_{2} \mathrm{ab}-$ sorption is applied through $\mathrm{NaOH}$ solution ( $3 \mathrm{M}$ ). The gas meter is equipped with a data acquisition system that the flow rate data is recorded continuously. The recorded data was logged as accumulated methane production volume and average methane production speed every hour for further analysis (Sambusiti et al. 2014).

To simulate and precisely quantify the multiple effects of TEs on methanogenesis of the two-phase AnMBR, an amount of $50 \mathrm{~mL}$ substrate (COD 23.21 $\pm 0.46 \mathrm{~g} \mathrm{~L}^{-1}$, VS 6.68 $\pm 0.17 \mathrm{~g} \mathrm{~L}^{-1}$ ) was mixed with $150 \mathrm{~mL}$ inoculum (COD 1.66 $\left.\pm 0.03 \mathrm{~g} \mathrm{~L}^{-1}, \mathrm{VS} 10.01 \pm 0.21 \mathrm{~g} \mathrm{~L}^{-1}\right)$ at OLR of $5.81 \pm 0.11 \mathrm{~kg}$ COD $\mathrm{m}^{-3}$ day $^{-1}$ for BMP tests. And then, TE stock solution was added as designed dosages described in the following "Experiments of TE supplementation" section. A blank group without substrate and another control group without TEs were performed, respectively. Initial $\mathrm{pH}$ value was around 7.4 for all mixtures. The reactor was purged with $\mathrm{N}_{2}$ for $3 \mathrm{~min}$ before each run to ensure anaerobic condition. The duration of BMP tests in this study was set at 7 days, which is that 2 days after methane production stopped (Zhang et al. 2014). The accumulated methane yield at 7 days $\left(B M P \mathrm{NmL} \mathrm{CH}_{4} \mathrm{~g}^{-1} \mathrm{VS}_{\mathrm{s}}\right)$ was calculated as Eq. 1 , where $V_{\mathrm{CH} 4, \mathrm{~S}}$ and $V_{\mathrm{CH} 4 \text {,blank }}(\mathrm{NmL}$ $\mathrm{CH}_{4}$, standard temperature and pressure) are the volumes of accumulated methane production from the experimental group and blank group in 7 days, $\mathrm{NmL} \mathrm{VS}_{\mathrm{s}}$ is the mass of VSs of the substrate, $g$.

$\mathrm{BMP}=\left(V_{\mathrm{CH}_{4} 5}-V_{\mathrm{CH}_{4}}\right.$, blank $) / \mathrm{VS}_{5}$

To evaluate the methane production activity induced by TEs, the maximum slope of accumulated methane production was taken for calculating SMA as maximum specific rate (Buntner et al. 2014). It is different from another SMA as kinetics coefficient $k$ in the first-order kinetics or the Monod model of methane productions (Strömberg et al. 2015), because the SMA as maximum specific rate has more links with the performance of the AnMBR under the biogas-pH control strategy (Yu et al. 2016). The methane production speed was used as the slope for accumulated methane production. The slope was calculated every $6 \mathrm{~h}$. The SMA $\left(\mathrm{NmL} \mathrm{CH}_{4} \mathrm{~g}^{-1}\right.$ $\mathrm{VS}_{\mathrm{i}} \mathrm{h}^{-1}$ ) was calculated as the maximum slope divided by VS of inoculum as Eq. 2, which is the maximum specific rate 
as an indicator of methanogenic activities, where $S_{\mathrm{CH} 4, \mathrm{~S}}$ and $S_{\mathrm{CH} 4 \text {,blank }}\left(\mathrm{NmL} \mathrm{h}^{-1} \mathrm{CH}_{4}\right.$, standard temperature and pressure) are the slopes of accumulated methane production per hour from the experimental group and blank group, respectively, $\mathrm{NmL} \mathrm{h}^{-1} \cdot \mathrm{VS}_{\mathrm{i}}$ is the mass of VS in inoculum.

$\mathrm{SMA}=\max \left[\operatorname{AVG}\left(\sum_{h=n}^{n=6}\left(S_{\mathrm{CH}_{4} \mathrm{~S}}-S_{\mathrm{CH}_{4}, \text { blank }}\right)\right)\right] / \mathrm{VS}_{\mathrm{i}}$

Each parallel run was measured at the end of the BMP test. The samples were centrifuged at $6000 \mathrm{rpm}$ for $8 \mathrm{~min}$ and filtered by $0.2 \mu \mathrm{m}$ membrane for SCOD and TOC/TIC analysis as shown in appendices. Biomass growths were calculated by VSS increase between ferments and inoculums comparably. COD removals were calculated by COD concentration decrease between ferments and substrates comparably.

\section{Experiments of TE supplementation}

Effects of TE supplementation with individual element and combination of $\mathrm{Fe}, \mathrm{Ni}, \mathrm{Co}, \mathrm{Cu}$ and $\mathrm{Zn}$ on methanogenesis of the two-phase AnMBR were evaluated as shown in Table 2. Three dosages $\left(0.02,2\right.$ and $\left.200 \mathrm{mg} \mathrm{L}^{-1}\right)$ were used in this study (Qiang et al. 2012; Qiao et al. 2013) to investigate the multiple effects of TE supplementation beyond stabilization (Table 2), and mixed supplementation of the three order levels was tested. Other two groups were also studied including a recovery group (TE31) from the inhibition group TE30 and a group based on TE requirements (TE40). The dosage of TEs (TE40, Table S1) was calculated according to TEs requirements of typical methanogenic microorganisms (Speece 1996) and checked with TE requirements of COD removal (Qiang et al. 2012). In the TE40 group, addition of individual TE was also performed to compare the different effects between individual or mixed supplements. Another object of TE40 is to compare its effects with the three consistent dose levels (TE10, TE20 and TE30).

A recovery group (Fig. S2, TE31) was tested for the highest dosing group (TE30). Inoculums of the recovery groups (Fig. S2, TE31) were anaerobic slurry from the TE30 groups, in which slurry was firstly centrifuged at $6000 \mathrm{rpm}$ for $8 \mathrm{~min}$ and slurry paste was collected for recovery tests. The extra TEs in the slurry paste were then washed three times with the effluent from the AnMBR, which is reported as a more balance recovery strategies (Nielsen and Angelidaki 2008). Substrate was added again without TE supplementation, and BMP tests were repeated.

The TE supplementation concentrations were calculated on TE ion concentration in solution which was regarded as approximately bioavailable form (Vintiloiu et al. 2013). The TEs were added in the form of the following salts as $\mathrm{Fe}^{2+}\left(\mathrm{FeCl}_{2}\right.$. $\left.4 \mathrm{H}_{2} \mathrm{O}\right), \mathrm{Ni}^{2+}\left(\mathrm{NiCl}_{2} \cdot 6 \mathrm{H}_{2} 0\right), \mathrm{Co}^{2+}\left(\mathrm{CoCl}_{2} \cdot 6 \mathrm{H}_{2} \mathrm{O}\right), \mathrm{Cu}^{2+}\left(\mathrm{CuCl}_{2}\right.$. $\left.2 \mathrm{H}_{2} \mathrm{O}\right)$ and $\mathrm{Zn}^{2+}\left(\mathrm{ZnCl}_{2}\right)$, respectively.

To make results more comparable in these test groups, all effects of TEs on methanogenesis were calculated as percentage (Strömberg et al. 2015); such as, effect of TE supplementation on methane production was calculated as Eq. (3):

Effect $=\left(\mathrm{BMP}_{7, \mathrm{TE}}-\mathrm{BMP}_{7, \text { Control }}\right) / \mathrm{BMP}_{7, \text { Control }} \times 100 \%$

\section{Microbial community analysis}

The microbial mechanism of TEs' multiple effects on methanogenesis of the two-phase AnMBR was studied by analysing microbial community structure (Vanwonterghem et al. 2014; Zhang et al. 2015). Microbial community structure was analysed in the recovery groups because their differentiation induced by TEs was more significant after twice AD. According to preliminary results in this work, both BMP and COD removal were stimulated in the recovery group with iron addition at $200 \mathrm{mg} \mathrm{L}^{-1}$. In contrary, both BMP and COD removal were greatly inhibited in the recovery group with copper addition at $200 \mathrm{mg} \mathrm{L}^{-1}$. Therefore, the recovery groups with both iron and copper addition (TE313, TE316) were selected for further microbial community and morphology evaluation. The mixed supplementation (TE318) of the recovery group was also selected for evaluating the interaction effects of TE addition.

Of each selected sample, $0.4 \mathrm{~g}$ (TE311, TE313, TE316 and TE318) was collected for DNA extraction according to protocols of the QIAamp DNA Stool Mini Kit (QIAGEN, USA). PCR primers 515F (GTGCCAGCMGCCGCGGTAA) and
Table 2 Dosage of trace element supplementation in the BMP tests

\begin{tabular}{lrlllllllll}
\hline $\begin{array}{l}\text { Group } \\
\text { ID }\end{array}$ & $\begin{array}{l}\text { Dosage } \\
\left(\mathrm{mg} \mathrm{L}^{-1}\right)\end{array}$ & $\begin{array}{l}\text { Blank (only } \\
\text { inoculum })\end{array}$ & Control & \multicolumn{2}{l}{ Trace elements effects } & & \\
\cline { 5 - 9 } & & & & $\mathrm{Fe}^{2+}$ & $\mathrm{Ni}^{2+}$ & $\mathrm{Co}^{2+}$ & $\mathrm{Cu}^{2+}$ & $\mathrm{Zn}^{2+}$ & Mixed $^{\text {b }}$ \\
\hline TE10 & 0.02 & TE101 & TE102 & TE103 & TE104 & TE105 & TE106 & TE107 & TE108 \\
TE20 & 2 & TE201 & TE202 & TE203 & TE204 & TE205 & TE206 & TE207 & TE208 \\
TE30 & 200 & TE301 & TE302 & TE303 & TE304 & TE305 & TE306 & TE307 & TE308 \\
TE31 & Recovery & TE311 & TE312 & TE313 & TE314 & TE315 & TE316 & TE317 & TE318 \\
TE40 & $160 \%{ }^{\mathrm{a}}$ & TE401 & TE402 & TE403 & TE404 & TE405 & TE406 & TE407 & TE408 \\
\hline
\end{tabular}

${ }^{a} 160 \%$ : supplementation at the ratio of trace elements in eight kinds of typical methanogens (see Table S1)

${ }^{\mathrm{b}}$ Mixed: mixed supplementation of every trace elements at the three order levels 
806R (GGACTACHVGGGTWTCTAAT) targeting the bacteria and archaeal 16S V4 region were selected for microbial community structure analysis (Caporaso et al. 2011), which were also used in Earth Microbiome Project (http://www. earthmicrobiome.org/). DNA was amplified following the protocol described previously (Caporaso et al. 2011). The size of PCR amplicons was determined by agarose gel electrophoresis. PCR amplicons were further purified with a DNA purification kit (BioFlux, Japan), and concentrations were determined using spectrometry NanoDrop-1000 (Thermo Scientific, USA). Amplicons from different samples were then mixed to achieve equal mass concentrations in the final mixture, which were sent out to Novogene Co., Ltd. in Beijing for small-fragment library construction and pair-end sequencing using an Illumina sequencing system (MiSeq, Illumina, USA).

Barcode and primers were removed from sequencing reads. Pairs of reads from the original DNA fragments were merged (Magoc and Salzberg 2011) and then filtered (Caporaso et al. 2011). PCR chimeras were filtered out using UCHIME. And then, the reads are "clean reads". The average length of all the clean reads was $276.05 \mathrm{bp}$. After the above filtration, the minimum number of selected sequences in the four samples was 30,578 . To fairly compare the four samples at the same sequencing depth, normalization of the sequence number was conducted by extracting the first 30,578 sequences in each sample for further analyses. And, all the normalized sequences were uploaded to MG-RAST (http://metagenomics.anl.gov/ linkin.cgi?project=13303). The taxonomic classification of the sequences of each sample was carried out individually using the RDP Classifier, and the sequences to different taxonomy levels were assigned at the bootstrap cut-off of $50 \%$ suggested by the RDP (Wang et al. 2007). In addition, the diversity and richness indices were calculated using the relevant RDP pipeline modules as previously (Zhang et al. 2015). Correlations between microbial community structures and their functions were analysed by redundancy analysis (RCA) method using CANOCO 5.0.

Sludge samples were pre-treated to fix morphology (Fang and Chui 1993). Observation of the microbial morphology with a field emission scanning electron microscopy (FESEM) (Hitachi S-4160, accelerating voltage of $15 \mathrm{kV}$ ) was also carried out. FE-SEM was operated under dry mode (10 Torr, dry biomass).

\section{Results}

\section{Effects of TEs on COD removal and methane production}

\section{COD removal}

The results of individual TE addition showed that the stimulation of COD removal was diverse at different dosages
(Fig. 2a). The COD removal rate was decreased by 11.9 $\pm 4.6 \%$ at $0.02 \mathrm{mg} \mathrm{L}^{-1}$ of cobalt addition, though all COD removal rates were slightly increased at TE dosage of $2 \mathrm{mg} \mathrm{L}^{-1}$ (TE20). Obviously, both COD removal and methane production were completely inhibited by the tests of mixed TE supplementation at $200 \mathrm{mg} \mathrm{L}^{-1}$. The highest COD removal rate of $78.6 \%$ was achieved in the recovery group of iron addition (TE313), and the COD removals in other recovery groups were well recovered except zinc.

\section{Methane production}

As shown in Fig. 2b, the methane production showed similar decreasing trend with TE dosages increasing in all test groups. The methane production in all tests of group TE10 $\left(0.02 \mathrm{mg} \mathrm{L}^{-1}\right)$ was increased, but the highest increasement and inhibition of the methane production were $7.5 \pm 0.6$ and $-19.2 \pm 7.2 \%$ at 0.02 and $200 \mathrm{mg} \mathrm{Cu} \mathrm{L}{ }^{-1}$, respectively. The dose-effect relationship was similar to copper in other individual TE addition except nickel. The individual nickel supplementation groups showed slight stimulation in all tested dosages, ranging from $1.1 \pm 0.7$ to $2.4 \pm 0.4 \%$. In the mixed TE addition group, effects of TE dosages on methane production were changed from stimulation to inhibition when dosages increased. The mixed TE supplementation of $0.02 \mathrm{mg} \mathrm{L}^{-1}$ stimulated the methane production by $4.1 \pm 0.9 \%$, lower than that of the copper addition $(7.5 \pm 0.6 \%)$ and zinc addition $(6.2$ $\pm 1.3 \%$ ) at dosage of $0.02 \mathrm{mg} \mathrm{L}^{-1}$. The mixed TE supplementation of $2 \mathrm{mg} \mathrm{L}^{-1}$ inhibited the methane production by -8.8 $\pm 0.4 \%$, worse than that of other individual TE supplementation of $2 \mathrm{mg} \mathrm{L}^{-1}$. Methanogenesis was completely inhibited in the mixed supplementation at dosage of $200 \mathrm{mg} \mathrm{L}^{-1}$, and the completely inhibited sample (TE308) was failed in methane production at the test of recovery group (TE318), which indicated irreversible inhibitions induced by the mixed TEs. This reversion from essentiality to toxicity widely exists because TEs are either key micronutrient or poisons dependent on their interaction and dosages. Other inhibitions in individual TE addition were mitigated in most of the recovery group, such as cobalt and zinc, but iron addition in the recovery group had even higher activity increment $(3.7 \pm 0.1 \%)$ other than mitigation. Mixed ratio showed higher inhibited effects $(-18.1$ $\pm 15.5 \%, 160 \%$ supplementation) than other mixed TE supplementation groups (TE108 and TE208).

\section{Multiple effects of TEs on methanogenesis}

As shown in Fig. 3, multiple effects of five TEs ( $\mathrm{Fe}, \mathrm{Ni}, \mathrm{Co}, \mathrm{Cu}$ and $\mathrm{Zn}$ ) on methanogenesis of the two-phase AnMBR treating starch wastewater, including methane production, activity of methanogenic microorganisms, biomass growth and COD removal, were calculated and compared uniformly according to their percentages of the control group, respectively, calculated 

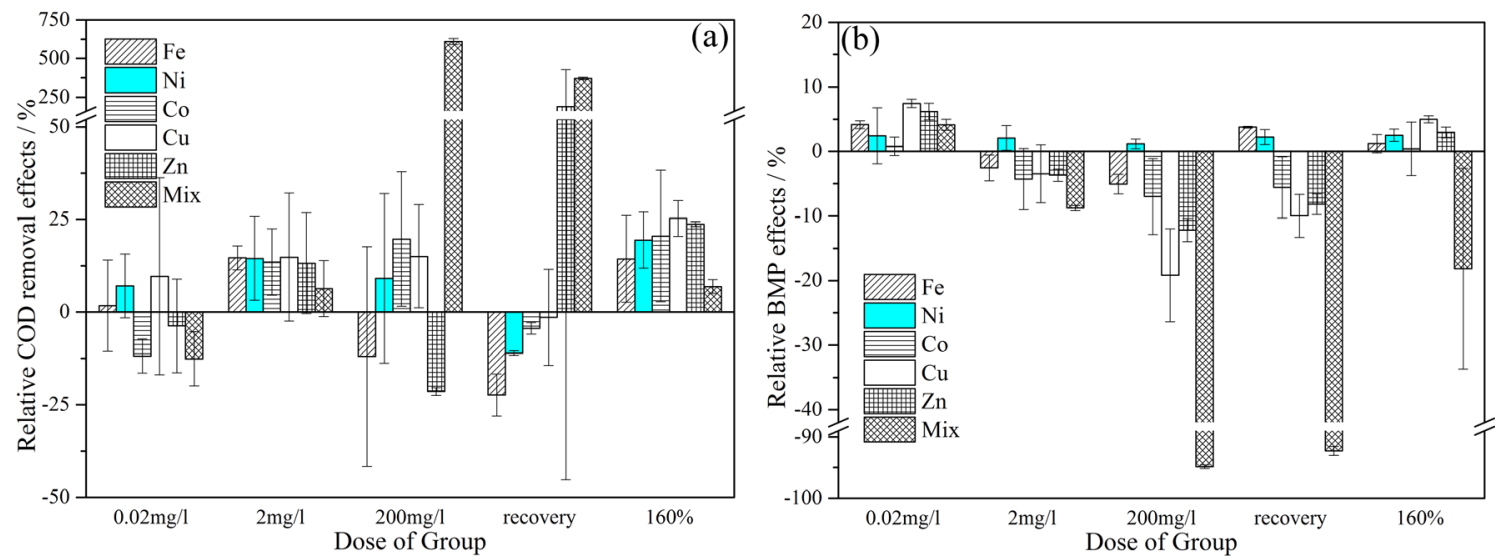

Fig. 2 Changing rates of different effects when trace elements added on a COD removal and $\mathbf{b}$ methane production in methanogenesis phase of a twophase AnMBR treating starch wastewater

by Eq. 2. In the dosage of TEs ranging from 0.02 to $200 \mathrm{mg} \mathrm{L}^{-1}$, most of the effects followed similar patterns as hotspots (a), (b), (c) and (d) in Fig. 3. The methane production was clustered at hotspot (a) including TE10 and TE40 at dosage of $0.02 \mathrm{mg} \mathrm{L}^{-1}$ and $160 \%$, respectively. The second hotspot (b) involved with the SMA clustered at the inhibition area from $70.0 \%$ (TE303, $200 \mathrm{mg} \mathrm{Fe} \mathrm{L}^{-1}$ ) to $143.1 \%$ (TE208, $2 \mathrm{mg}$ mix $\mathrm{L}^{-1}$ ) in different groups except the iron and mixed groups. The third hotspot (c) involved with biomass growth of inoculum which was clustered at slight stimulation area in all groups. The fourth hotspot (d) was involved with COD removal, which was clustered at the simulation area in groups of TE10 and TE40 at dosage of $0.02 \mathrm{mg} \mathrm{L}^{-1}$ and $160 \%$, similar to the results of methane production clustered at the hotspot (a).

It is clear that dosage of TEs played more important roles than species in biomass growth and COD removal as shown in Fig. 3. The COD removal and methane production were stimulated simultaneously at the hotspot (a) and hotspot (d) at dosage of $0.02 \mathrm{mg} \mathrm{L}^{-1}$ and $160 \%$, respectively. The SMA was inhibited, and the biomass growth was stimulated in most of these two hotspots. The phenomena were different from the typical reports of TE stimulation methane production activity at low dosage (Florencio et al. 1993). In this study, TE supplementation inhibited the SMA but stimulated the COD removal, methane production and biomass growth, which was in accordance with the mechanism of enzyme re-activation.

\section{Microbiology mechanism of TEs affecting methanogenesis}

\section{Methanation activity}

Although the positive impact of TE supplement is smaller than previously reported results (Lindorfer et al. 2012), effects of TE supplementation on SMA and COD removal were still obvious. The metabolic activity of methanogens is shown in Fig. $4 \mathrm{a}$ by the SMA in individual and mixed addition groups.

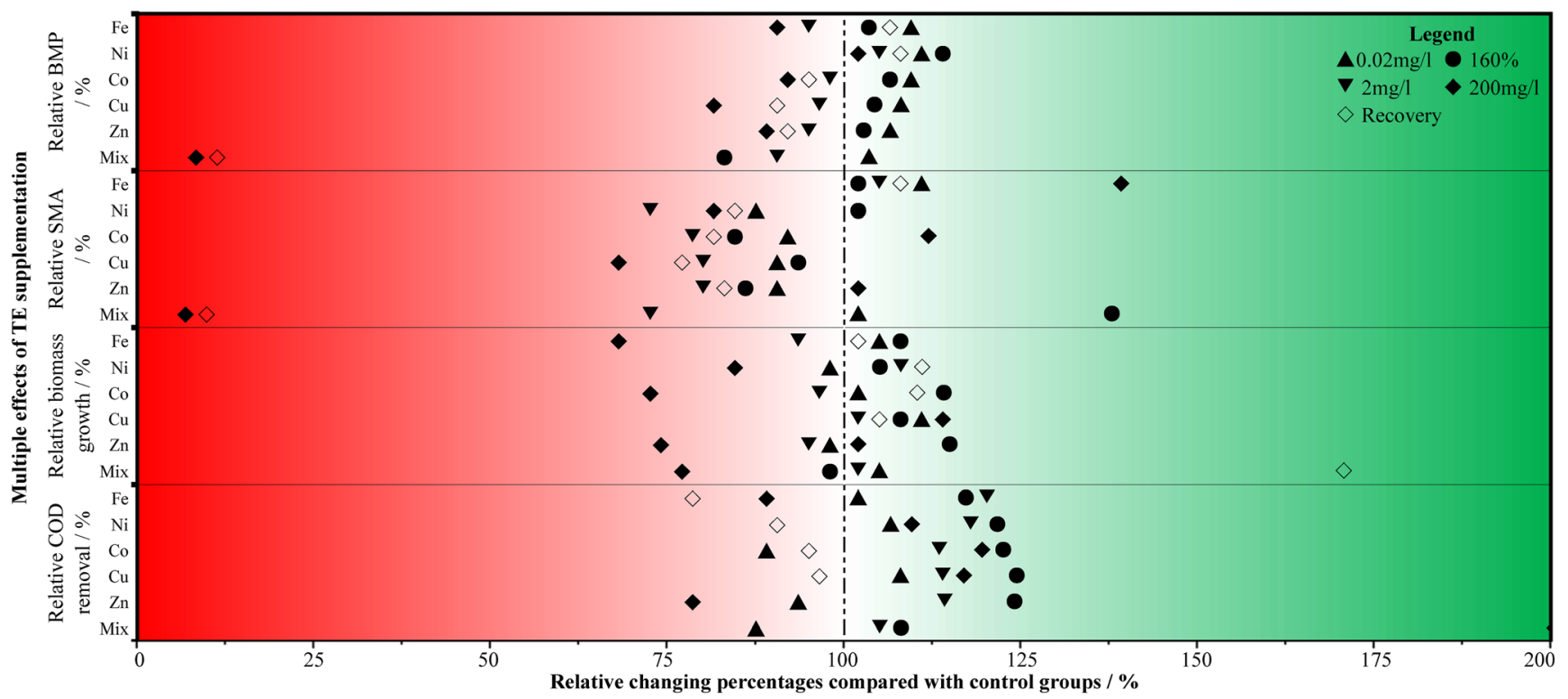

Fig. 3 Stimulation, tolerance and inhibition of TEs on methanogenesis, and circles (a) (b) (c) (d) are hotspots 

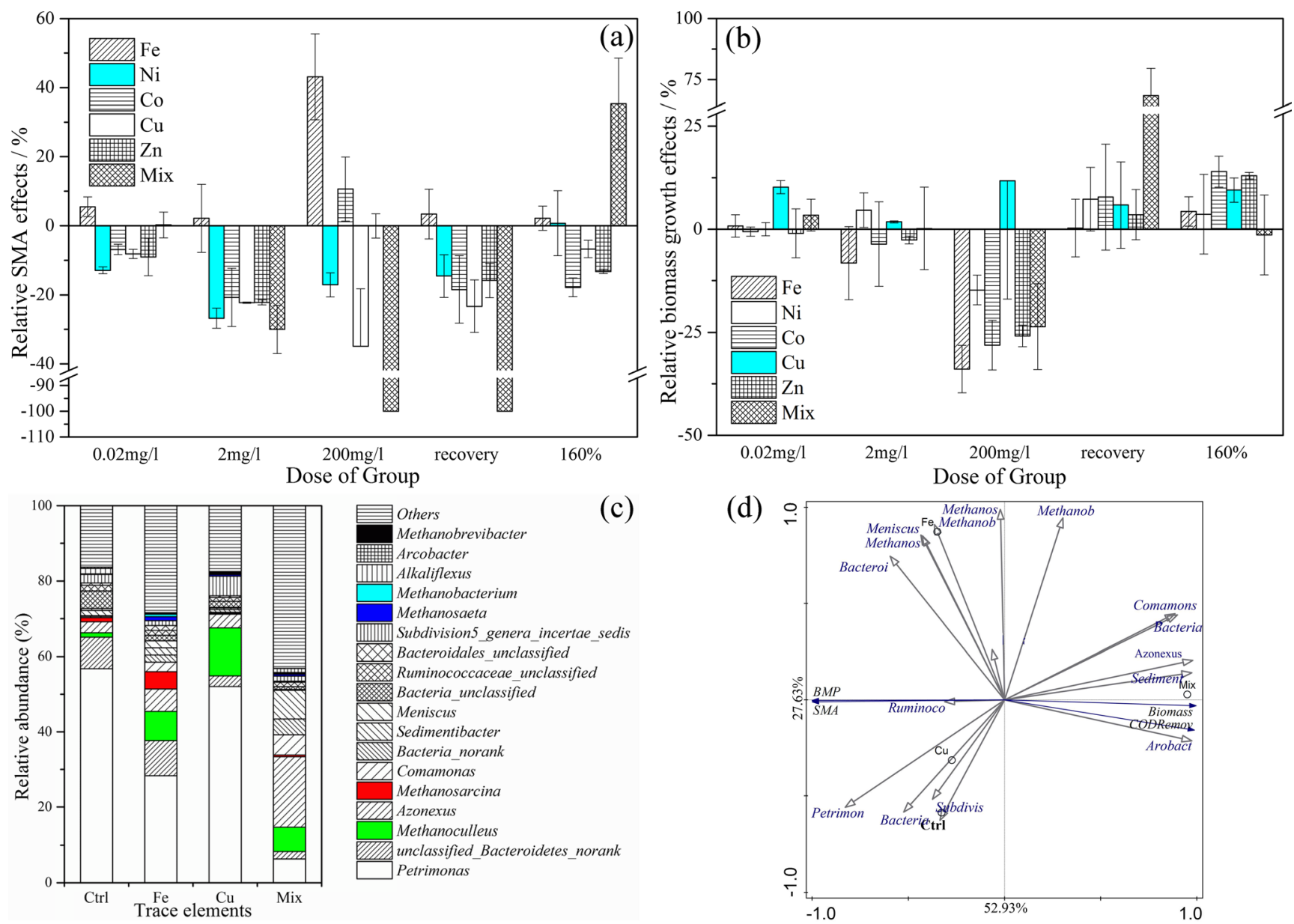

Fig. 4 Effects of TEs on a SMA and their mechanism of methanogen growth, $\mathbf{b}$ biomass growth, $\mathbf{c}$ microbial community structure and $\mathbf{d}$ RCA analysis between microbial species and their functions

The results of SMA showed inhibition occurrence in most of dosage groups. Among these inhibitions, the SMA was decreased by $34.9 \pm 16.7 \%$ at $200 \mathrm{mg} \mathrm{L}^{-1}$ of copper addition, which was the worst case. Meanwhile, other dosages $(0.02$ and $2 \mathrm{mg} \mathrm{L}^{-1}$ ) of copper showed inhibition of the SMA. In contrast, all tests of iron dosages ranging from 0.02 to $200 \mathrm{mg} \mathrm{L}^{-1}$ showed stimulation for the SMA, and the highest SMA $\left(577.56 \pm 50.30 \mathrm{~mL} \mathrm{CH}_{4} \mathrm{~g} \mathrm{VSS}^{-1}\right.$ day $\left.^{-1}\right)$ occurred at $200 \mathrm{mg} \mathrm{L}^{-1}$ (TE303) of iron addition in this study. Comparing with the inhibition of individual TE addition tests, supplementation of TEs mixed at a given proper ratio could stimulate the SMA by $35.3 \pm 13.3 \%$. This result may attribute to that methane is a product of complex metabolic pathway, and inhibition in the individual TE addition could be attributed to lack of more than one key TE for enzyme or coenzyme (Zhang and Jahng 2012). Diversity results of the recovery group occurred at different dosages. After the highest stimulation at $200 \mathrm{mg} \mathrm{L}^{-1}$ of iron dosage, the SMA of the TE313 recovery test still remained higher stimulation than other TEs because the SMAs of other recovery groups were all inhibited. The mixed group at high dosage (200 $\mathrm{mg} \mathrm{L}^{-1}$, TE308) completely inhibited methane production, and SMA of the related recovery group TE318 did not recover even after washing out TEs.

Based on the abovementioned results, TEs are whether micronutrition or poisons depending on dosage, especially in the mixed group. Iron and copper in this study were not only very effective in enhancement of methane production, SMA and COD removal, but also easy to obtain in practice.

\section{Methanogen growth}

Mechanisms of methanation activity stimulations were attributed to methanogen growths which were found expressions in three ways: (1) total biomass increment as VS increment compared with inoculums, (2) methanogen functional archaea increment as relative abundance raised and (3) methanogen functional archaea increment as their size enlarged in morphology. As shown in Fig. 4b, biomass growth was changed a lot with TEs' dosages increasing from 0.02 to $200 \mathrm{mg} \mathrm{L}^{-1}$ in individual TE supplementation except copper. Copper stimulated the biomass growth among dosages from 0.02 to $200 \mathrm{mg} \mathrm{L}^{-1}$, and the strongest stimulation of biomass growth was $10.2 \pm 1.6 \%$ which occurred at $0.02 \mathrm{mg} \mathrm{Cu} \mathrm{L}^{-1}$, but other 
dosages of copper had shown stimulation from $1.8 \pm 0.2 \%$ $\left(2 \mathrm{mg} \mathrm{Cu} \mathrm{L}^{-1}\right)$ to $11.7 \pm 28.6 \%\left(200 \mathrm{mg} \mathrm{Cu} \mathrm{L}^{-1}\right)$. The biomass growth stimulation and the BMP inhibition indicated that copper might turn more removed substrates to biomass (and carbon dioxide) rather than methane, which needs more investigation on its multiple effects. With the dosage increasing, the biomass growth was shifted from slight stimulations to inhibitions; e.g. the inhibition of biomass growth was shifted from $-0.8 \pm 2.7 \%$ at $0.02 \mathrm{mg} \mathrm{Fe} \mathrm{L}^{-1}$ to $-33.9 \pm 5.7 \%$ at $200 \mathrm{mg}$ $\mathrm{Fe} \mathrm{L}^{-1}$. After inhibition in the TE30 $\left(200 \mathrm{mg} \mathrm{L}^{-1}\right)$ group, these inhibitions of biomass growth were mitigated in the recovery group (TE31). Both the recovery (TE31) and $160 \%$ (TE40) groups were tended to stimulate biomass growth. Compared with individual TE supplementation, mixed TE supplementation did not show synergistic effects in biomass growth. The mechanism of biomass growths was in accordance with most low-dosage TE. For example, both biomass growth and SMA were stimulated at $0.02 \mathrm{mg} \mathrm{Fe} \mathrm{L}{ }^{-1}$, because the SMA was improved by new growth of biomass (Zandvoort et al. 2006).

As shown in Fig. 4c, results showed that the relative abundance of methanation functional microorganisms changed a lot in both iron and copper addition groups. Dominant microbial communities were Methanosarcina, Methanoculleus and Methanobacterium in the iron recovery group, which were also correlation suggested by RCA results (Fig. 4d).
Methanosarcina was reported for the high activity of methane production which was stimulated by iron (Karlsson et al. 2012). These results showed that iron addition stimulated the methanation activity by enriching critical methanation functional microorganisms. Methanoculleus was reported as saline tolerance and correlated with TE supplementation (Feng et al. 2010), which was stimulated by copper and mixed TE group. Methanoculleus was dominated in the recovery group of mixed TE supplementation in which methanation was completely inhibited. Both Methanoculleus and biomass growth were stimulated in the tests of copper group, but the activity was still inhibited according to SMA results. The microbial community structure results showed that TE supplementations were critical to increase of relative abundance and decrease of methanation functional microorganism, which was also the key microbial mechanism of SMA stimulation and inhibition. For example, the SMA in this study was stimulated at $200 \mathrm{mg} \mathrm{Fe} \mathrm{L}^{-1}$ when the biomass growth inhibited, which could be explained by the relative abundance increase of Methanosarcina (Karlsson et al. 2012).

FE-SEM analysis was carried out in the same group with microbial community analysis to validate the hypothesis that morphology enlarging is induced by extra TEs. As shown in Fig. 4c, iron promoted Methanosarcina recovery in both amount (increased from 1 to $4 \%$ ) and enlarged size (Fig. 5b).

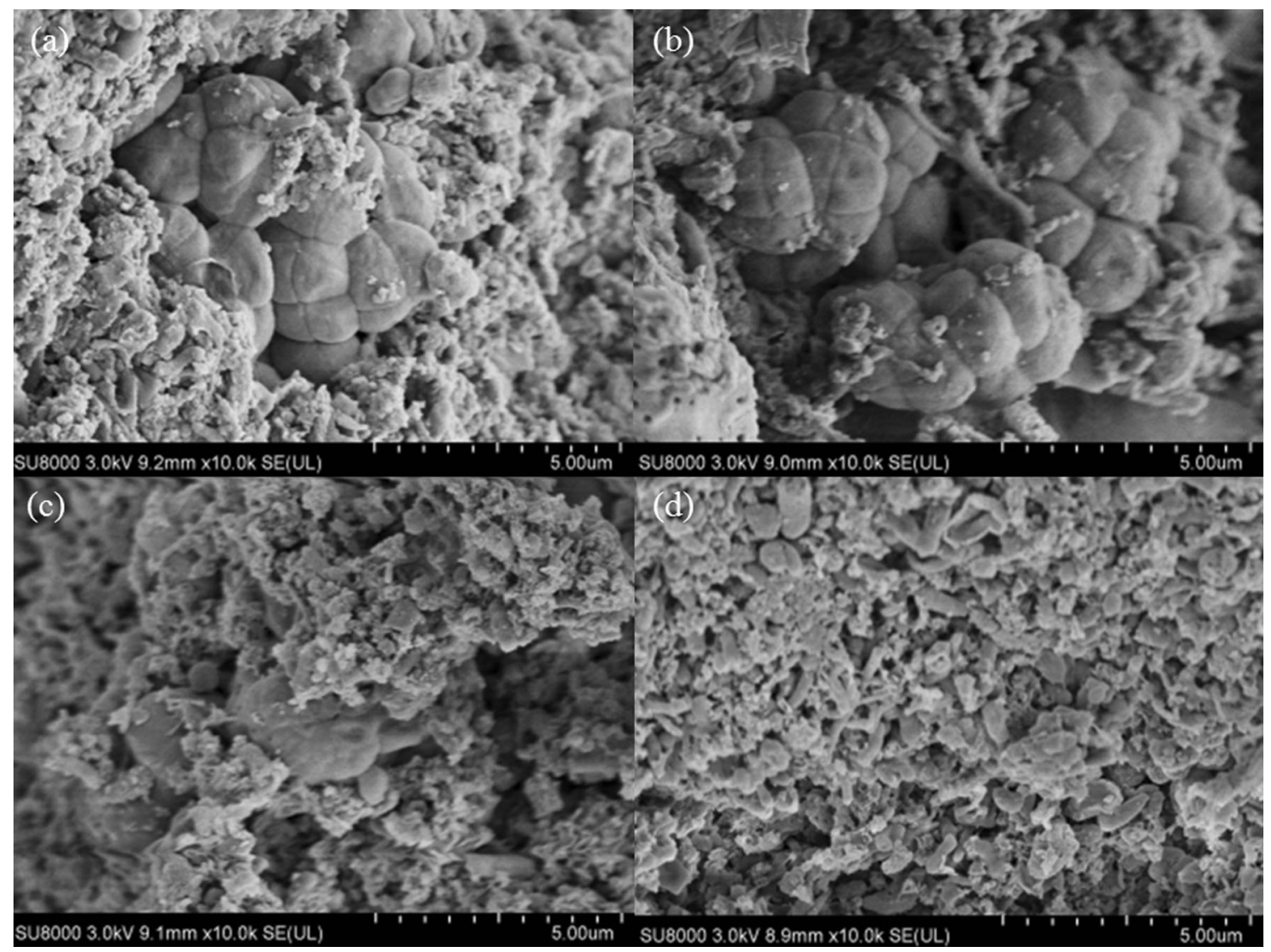

Fig. 5 FE-SEM results ( $\sim 100 \mathrm{k})$ of biomass in the recovery groups: a control, $\mathbf{b} \mathrm{Fe}, \mathbf{c} \mathrm{Cu}$ and $\mathbf{d}$ mixed 
Methanosarcina in the iron group seemed not only twice larger than that in copper group, but also much more effective in fission than that in other groups. Iron stimulated morphology enlarging of Methanosarcina. Copper addition reduced the size of Methanosarcina (Fig. 5c). Methanosarcina and other methanation functional bacteria were barely seen in the mixed groups (Fig. 5d). It was obvious that high concentration of mixed TEs inhibited methanogens completely even the inhibitors were washed out. The mechanism of size enlargement was also in accordance with some TE. For example, the SMA in this study was inhibited at $200 \mathrm{mg} \mathrm{Cu} \mathrm{L}^{-1}$ though both the biomass growth and relative abundance of Methanoculleus were stimulated; its size was decreased.

\section{Discussions}

These multiple effects showed the potential of TE supplement in improvement of the AnMBR performance. Different from the reported stimulation situation (Lindorfer et al. 2012), TE addition in the two-phase AnMBR treating starch wastewater stimulated the methanogenesis beyond stabilization and methane production. The results clearly suggest that $\mathrm{AD}$ of starch wastewater (Fang et al. 2011) can also be benefited from TE addition not only on methane production, but also on COD removal and SMA increase. The investigated mechanisms of SMA increasement including biomass increasement, functional archaea increment by abundance and size in the work. But there are still further mechanisms researches needed in activity of metal-enzymatic (Sambusiti et al. 2014; Scheller et al. 2010) and bioavailability of trace metals (Vintiloiu et al. 2013). And, multiple effects of TEs on AD can be optimized by carefully choosing species and doses (Qiang et al. 2012). Therefore, proper adding of TEs for AnMBR treating food processing wastewater at high COD strength could stimulate more COD bioconvert to methane which brings lower COD concentration of effluent at around $300 \mathrm{mg} \mathrm{L}^{-1}$, and thus, the downstream treatment or directly discharging could be benefited.

The supplement strategy of TEs should be considered broadly rather than stabilization of $\mathrm{AD}$. Recent researches put considerable emphasis on the species of different TEs for enzyme catalysis, because TEs could be components, active centre or activator of enzyme or coenzyme. Nickel is a component of methyl-coenzyme M reductase (MCR) (Scheller et al. 2010). Copper is the active centre of methane monooxygenase (Murrell et al. 2000). What is more, recent researches in metaproteomics and metabolomics showed that the metabolism networks of $\mathrm{AD}$ are related to cooperation of many pathways (Vanwonterghem et al. 2014). In another aspect, chemical forms and transformation of TEs were also critical to their effects, such as bioavailable forms and metal sulphide (Ahring 2003). So, the balances of multiple effects still need to be evaluated by more studies in various indicators for different purposes according to the digestion system. Additionally, the discharging standard of TEs and its potential environmental risk also need to be assessed in further researches as TEs are more widely used in $\mathrm{AD}$ treating food waste recently.

The mechanisms of activity increase indicated that adding strategies of TE could be more flex according to precision object as TE supplements also increasing risk of heavy metal emission. In traditional anaerobic digester, long-term additions of TEs were often applied to increase the stability of high-rate AD (Wei et al. 2014a). This element, for example Fe, has a relatively high composition percentage in a cell, and demanded amount for $\mathrm{Fe}$ absorption by the cell was higher than other metals (Qiang et al. 2012). Ni and Co have been identified as two very important trace metals for methanogenesis (Qiang et al. 2012). And also, $\mathrm{Ni}, \mathrm{Co}, \mathrm{Cu}$ and $\mathrm{Zn}$ are in the category of heavy metals which has toxic effect on methanogenesis at high concentration. However, the AnMBR could retain sludge effectively by membrane; thus, a more environmental friendly and efficient strategy for long-term operation of AnMBR treating food processing wastewater may be intermittent supplementation of TEs. Therefore, it is more environmental friendly and efficient strategy that intermittent supplementation of $200 \mathrm{mg} \mathrm{Fe} \mathrm{L}^{-1}$ after the sludge discharging, rather than maintained a stable dosage of $2 \mathrm{mg} \mathrm{Fe} \mathrm{L}^{-1}$ (Fig. 2). By this intermittent supplementation strategy, minimized iron dosing and stimulated multiple effects could be simultaneously achieved in the methanogenesis, which will be very attractive in both rapid establishment and online recovery of the AnMBR treating food processing wastewater.

Acknowledgments This work was funded by Major Science and Technology Program for Water Pollution Control and Treatment of China (2012ZX07203-002; 2015ZX07203-005) and China-EU Innovation Funding for Small and Medium Size Enterprise (SQ2013ZOA000002). The authors also would like to thank Mingxing Zhao for English proofreading.

\section{Compliance with ethical standards}

Human and animal rights and informed consent This article does not contain any studies with human participants or animals performed by any of the authors.

Conflict of interest The authors declare that there are no conflicts of interest.

\section{References}

Ahring BK (2003) Biomethanation I, vol 81. Springer, Berlin

Buntner D, Spanjers H, van Lier JB (2014) The influence of hydrolysis induced biopolymers from recycled aerobic sludge on specific methanogenic activity and sludge filterability in an anaerobic membrane bioreactor. Water Res 51:284-292. doi:10.1016/j.watres.2013.10.065

Caporaso JG, Lauber CL, Walters WA, Berg-Lyons D, Lozupone CA, Turnbaugh PJ, Fierer N, Knight R (2011) Global patterns of 16S rRNA diversity at a depth of millions of sequences per sample. Proc 
Natl Acad Sci U S A 108(Suppl 1):4516-4522. doi:10.1073/pnas. 1000080107

Chen Y, Cheng JJ, Creamer KS (2008) Inhibition of anaerobic digestion process: a review. Bioresour Technol 99(10):4044-4064. doi:10. 1016/j.biortech.2007.01.057

Fang HHP, Chui HK (1993) Microstructural analysis of anaerobic granules. Biotechnol Tech 7(7):407-410. doi:10.1007/Bf00151874

Fang C, Boe K, Angelidaki I (2011) Biogas production from potato-juice, a by-product from potato-starch processing, in upflow anaerobic sludge blanket (UASB) and expanded granular sludge bed (EGSB) reactors. Bioresour Technol 102(10):5734-5741. doi:10. 1016/j.biortech.2011.03.013

Feng XM, Karlsson A, Svensson BH, Bertilsson S (2010) Impact of trace element addition on biogas production from food industrial wastelinking process to microbial communities. FEMS Microbiol Ecol 74(1):226-240. doi:10.1111/j.1574-6941.2010.00932.x

Florencio L, Jeniček P, Field JA, Lettinga G (1993) Effect of cobalt on the anaerobic degradation of methanol. J Ferment Bioeng 75(5):368 374. doi:10.1016/0922-338X(93)90136-V

Han S-S, Bae T-H, Jang G-G, Tak T-M (2005) Influence of sludge retention time on membrane fouling and bioactivities in membrane bioreactor system. Process Biochem 40(7):2393-2400. doi:10.1016/j. procbio.2004.09.017

Ho J, Sung S (2010) Methanogenic activities in anaerobic membrane bioreactors (AnMBR) treating synthetic municipal wastewater. Bioresour Technol 101(7):2191-2196. doi:10.1016/j.biortech. 2009.11.042

Karlsson A, Einarsson P, Schnürer A, Sundberg C, Ejlertsson J, Svensson BH (2012) Impact of trace element addition on degradation efficiency of volatile fatty acids, oleic acid and phenyl acetate and on microbial populations in a biogas digester. J Biosci Bioeng 114(4): 446-452. doi:10.1016/j.jbiosc.2012.05.010

Lindorfer H, Ramhold D, Frauz B (2012) Nutrient and trace element supply in anaerobic digestion plants and effect of trace element application. Water Sci Technol 66(9):1923-1929. doi:10.2166/wst. 2012.399

Magoc T, Salzberg SL (2011) FLASH: fast length adjustment of short reads to improve genome assemblies. Bioinformatics 27(21):29572963. doi:10.1093/bioinformatics/btr507

Mao CL, Feng YZ, Wang XJ, Ren GX (2015) Review on research achievements of biogas from anaerobic digestion. Renew Sust Energ Rev 45:540-555. doi:10.1016/j.rser.2015.02.032

Ministry of Environmental Protection (2015) Environment statistical yearbook (2013). In: yearbook Es (ed). Ministry of Environmental Protection, Beijing

Murrell JC, McDonald IR, Gilbert B (2000) Regulation of expression of methane monooxygenases by copper ions. Trends Microbiol 8(5): 221-225

Nielsen HB, Angelidaki I (2008) Strategies for optimizing recovery of the biogas process following ammonia inhibition. Bioresour Technol 99(17):7995-8001. doi:10.1016/j.biortech.2008.03.049

Osuna MB, Zandvoort MH, Iza JM, Lettinga G, Lens PNL (2003) Effects of trace element addition on volatile fatty acid conversions in anaerobic granular sludge reactors. Environ Technol 24(5):573-587

Padmasiri SI, Zhang J, Fitch M, Norddahl B, Morgenroth E, Raskin L (2007) Methanogenic population dynamics and performance of an anaerobic membrane bioreactor (AnMBR) treating swine manure under high shear conditions. Water Res 41(1):134-144. doi:10. 1016/j.watres.2006.09.021

Qiang H, Lang D-L, Li Y-Y (2012) High-solid mesophilic methane fermentation of food waste with an emphasis on iron, cobalt, and nickel requirements. Bioresour Technol 103(1):21-27. doi:10.1016/j. biortech.2011.09.036

Qiao W, Takayanagi K, Shofie M, Niu Q, Yu HQ, Li Y-Y (2013) Thermophilic anaerobic digestion of coffee grounds with and without waste activated sludge as co-substrate using a submerged
AnMBR: system amendments and membrane performance. Bioresour Technol 150:249-258. doi:10.1016/j.biortech.2013.10. 002

Sambusiti C, Rollini M, Ficara E, Musatti A, Manzoni M, Malpei F (2014) Enzymatic and metabolic activities of four anaerobic sludges and their impact on methane production from ensiled sorghum forage. Bioresour Technol 155:122-128. doi:10.1016/j.biortech. 2013.12.055

Scheller S, Goenrich M, Boecher R, Thauer RK, Jaun B (2010) The key nickel enzyme of methanogenesis catalyses the anaerobic oxidation of methane. Nature 465(7298):606-U97. doi:10.1038/nature09015

Smith AL, Stadler LB, Cao L, Love NG, Raskin L, Skerlos SJ (2014) Navigating wastewater energy recovery strategies: a life cycle comparison of anaerobic membrane bioreactor and conventional treatment systems with anaerobic digestion. Environ Sci Technol 48(10): 5972-5981. doi:10.1021/es5006169

Speece RE (1996) Anaerobic biotechnology for industrial wastewaters. Archae Press, Nashville

State Council of China (2015) The action plan for water pollution prevention and control.

Strömberg S, Nistor M, Liu J (2015) Early prediction of biochemical methane potential through statistical and kinetic modelling of initial gas production. Bioresour Technol 176:233-241. doi:10.1016/j. biortech.2014.11.033

Vanwonterghem I, Jensen PD, Ho DP, Batstone DJ, Tyson GW (2014) Linking microbial community structure, interactions and function in anaerobic digesters using new molecular techniques. Curr Opin Biotechnol 27:55-64. doi:10.1016/j.copbio.2013.11.004

Vintiloiu A, Boxriker M, Lemmer A, Oechsner H, Jungbluth T, Mathies E, Ramhold D (2013) Effect of ethylenediaminetetraacetic acid (EDTA) on the bioavailability of trace elements during anaerobic digestion. Chem Eng J 223:436-441. doi: 10.1016/j.cej.2013.02.104

Wall DM, Allen E, Straccialini B, O'Kiely P, Murphy JD (2014) The effect of trace element addition to mono-digestion of grass silage at high organic loading rates. Bioresour Technol 172:349-355. doi: 10.1016/j.biortech.2014.09.066

Wang Q, Garrity GM, Tiedje JM, Cole JR (2007) Naive Bayesian classifier for rapid assignment of rRNA sequences into the new bacterial taxonomy. Appl Environ Microbiol 73(16):5261-5267. doi:10. 1128/Aem.00062-07

Wei Q, Zhang W, Guo J, Wu S, Tan T, Wang F, Dong R (2014a) Performance and kinetic evaluation of a semi-continuously fed anaerobic digester treating food waste: effect of trace elements on the digester recovery and stability. Chemosphere 117:477-485. doi:10. 1016/j.chemosphere.2014.08.060

Wei YS, Yu DW, Chao L (2014b) Anaerobic membrane bioreactors for treating agricultural and food processing wastewater at high strength. Environ Sci 35(4):1613-1622. doi:10.13227/j.hjkx.2014. 04.058

Yanagi C, Sato M, Takahara Y (1994) Treatment of wheat starch waste water by a membrane combined two phase methane fermentation system. Desalination 98(1):161-170

Yu D, Liu J, Sui Q, Wei Y (2016) Biogas-pH automation control strategy for optimizing organic loading rate of anaerobic membrane bioreactor treating high COD wastewater. Bioresour Technol 203:62-70. doi:10.1016/j.biortech.2015.12.010

Zandvoort MH, van Hullebusch ED, Gieteling J, Lens PNL (2006) Granular sludge in full-scale anaerobic bioreactors: trace element content and deficiencies. Enzym Microb Technol 39(2):337-346. doi:10.1016/j.enzmictec.2006.03.034

Zhang L, Jahng D (2012) Long-term anaerobic digestion of food waste stabilized by trace elements. Waste Manag 32(8):1509-1515. doi: 10.1016/j.wasman.2012.03.015 
Zhang W, Lang Q, Wu S, Li W, Bah H, Dong R (2014) Anaerobic digestion characteristics of pig manures depending on various growth stages and initial substrate concentrations in a scaled pig farm in Southern China. Bioresour Technol 156:63-69. doi:10. 1016/j.biortech.2014.01.013
Zhang J, Cai X, Qi L, Shao C, Lin Y, Zhang J, Zhang Y, Shen P, Wei Y (2015) Effects of aeration strategy on the evolution of dissolved organic matter (DOM) and microbial community structure during sludge bio-drying. Appl Microbiol Biotechnol 99:7321-7331. doi: 10.1007/s00253-015-6640-Z 